\title{
LABATE, Beatriz Caiuby; GOULART, Sandra Lúcia. 0 uso de plantas Psicoativas nas Américas. Rio de Janeiro: Gramma/NEIP, 2019.
}

\section{GLAUBER LOURES DE ASSIS}

Na aurora do século XX, a sociedade moderna apresentava terreno muito fértil para as ciências sociais, que se maravilhavam e se debruçavam sobre suas peculiaridades e potencialidades. Naquele contexto, ganharam destaque como objeto de reflexão, dentre outros temas, a metrópole e sua vida mental; as teorias sobre a secularização, que em suas versões "duras" apregoavam o fim da religião; e as ideias de "desencantamento do mundo" e da racionalização da vida, que vinculavam o "espírito" do capitalismo ocidental ao protestantismo calvinista. Tal conjuntura também foi palco da Comissão do Ópio de Xangai (1909) e do estabelecimento da "guerra às drogas" e da política proibicionista em relação ao uso de psicoativos.

Agora, nesse início do século XXI, cem anos após a publicação da segunda edição da "Ética Protestante" de Max Weber (1920), as ciências sociais vislumbram novamente um horizonte bastante sui generis, e muito menos panglossiano. Em lugar da colonização interplanetária profetizada por cientistas ao longo do século XX, um dramático retorno à condição de terranos; em vez do triunfo do iluminismo laico e secular e da ciência como remédio para os males do mundo, o fortalecimento de identidades e disputas religiosas e o retorno a práticas e terapias de caráter mágico.

A religião, aliás, não só não sucumbiu, como tem se tornado mais difusa e multifacetada, com a crescente exportação de formas religiosas dos países do hemisfério sul para o norte global e a emergência da religiosidade "Nova Era", de uma espiritualidade enteógena urbana e de um intenso trânsito neoxamânico impulsionado pelo o renascimento do uso de psicodélicos na sociedade ocidental. Estes aspectos questionam o "desencantamento do mundo" e o "racionalismo" que povoaram os trabalhos acadêmicos no último século.

Nesse novo horizonte tão complexo quanto incerto, os limites e desafios do Antropoceno se tornam uma chave teórica fundamental para as ciências sociais. Estas têm a tarefa inglória de superar a profissão de fé antropo e etnocêntrica ocidental, a qual pressupõe o homo sapiens como ator cósmico mais central e relevante e o Ocidente como único modelo sociocultural desejável e/ou possível, cuja marcha em direção ao racionalismo e secularização seria uma lei histórica inexorável. Nesse contexto incerto e complexo, abordagens teóricas e etnográficas que reconhecem a importância da relação entre seres

\footnotetext{
${ }^{1}$ Doutor em sociologia pela UFMG.
} 
humanos e não humanos, a agência das plantas e animais e a descolonização da ciência se renovam e adquirem papel fundamental para a compreensão da(s) realidade(s).

Nesse novo Zeitgeist antropológico, plantas com propriedades psicodélicas tornamse um objeto especialmente relevante de pesquisa, e estudos sobre plantas psicoativas passam a ganhar relevo, na medida em que estas ocupam papel de destaque e mesmo central em diferentes culturas, distintos povos indígenas e diversos grupos urbanos. No horizonte contemporâneo, plantas psicoativas vivem seu próprio processo de diáspora e vêm sendo exportadas, difundidas e internacionalizadas sob diferentes formas. Trata-se de um processo permeado de polêmicas e conflitos jurídicos e religiosos, que problematizam a questão das drogas e da própria religiosidade/espiritualidade na sociedade globalizada.

O livro O uso de plantas psicoativas nas Américas (LABATE; GOULART, 2019) lança luz sobre essas e outras questões, reunindo 17 artigos com um total de 19 autores que se propõem à tarefa de refletir sobre as relações estabelecidas entre seres humanos e plantas psicoativas em diferentes países e povos do grande continente americano. Trata-se, em muitos sentidos, de uma obra pioneira e original, relevante para estudiosos de campos diversos que vão da etnologia indígena à filosofia, passando pela política de drogas e os (neo)xamanismos contemporâneos.

Esse projeto intelectual de fôlego é resultado da pioneira conferência internacional Jornadas Plantas Sagradas em Perspectiva, realizada na Universidade Estadual de Campinas em agosto de 2016, que mobilizou artífices das mais variadas áreas de estudos sobre plantas psicoativas. O ponto dissonante é que, enquanto a conferência teve um caráter marcadamente transdisciplinar, com apresentações de estudos que incluíam as ciências da saúde, o livro em questão se dedica exclusivamente a artigos e pesquisas das ciências humanas, com enfoque na etnologia. Tal opção faz da coletânea uma importante defesa do papel e da relevância das ciências sociais para a estudo do uso e dos significados das plantas psicoativas em um cenário onde predominam as interpretações farmacológicas, e em que há cada vez mais hegemonia de estudos, pesquisas e atores das áreas médica e biomédica, cujo capital simbólico confere poder e lugar de fala instantâneo a seus representantes.

Em prefácio inspirado, Esther Jean Langdon diz que "o livro é sobre cosmopolítica" (p. 9). Troque-se a preposição. Pois este é um livro de cosmopolítica (STENGERS, 2018), que ecoa também a identidade e o ativismo do NEIP - Núcleo de Estudos Interdisciplinares sobre Psicoativos, rede autônoma de pesquisadores da qual as organizadoras da coletânea são membros e fundadoras. Trata-se, portanto, de uma obra que não só mapeia e procura compreender a multiplicidade e riqueza de usos de plantas psicoativas, mas também valoriza e defende os conhecimentos indígenas e das populações tradicionais sobre as mesmas, e a própria agência das plantas em sua interação com seres humanos, reposicionando o papel da antropologia e da etnografia nesse(s) universo(s). Afinal, há muito mais coisas entre os 
humanos e plantas do que sonha nossa vã farmacologia. Plantas psicoativas não comportam somente moléculas, mas também seres e saberes, e sua relação com os humanos não se resume a interações bioquímicas, mas envolve diplomacia, ensino, predação, conflito, amizade e companheirismo.

A obra destaca tudo isso em quase duas dezenas de artigos de autores com diferentes formações e abordagens, que dialogam com matrizes teóricas contemporâneas como o perspectivismo (VIVEIROS DE CASTRO, 1996), a teoria ator-rede (LATOUR, 2012) e os estudos sobre gênero. Tal heterogeneidade de perspectivas não prejudica a coesão; pelo contrário, configura a unidade e inovação do livro, que traz estudos sobre uma diversidade relativamente grande de contextos e plantas (algumas delas pouco estudadas até o momento) e organiza seus capítulos em duas seções temáticas distintas.

A primeira delas, intitulada "Usos indígenas", é a mais original e orgânica, embora ligeiramente menor que a segunda. Destaca os usos, por diferentes populações indígenas, de diferentes plantas amazônicas e fungos psicoativos mexicanos. As contribuições originais do volume já aparecem no primeiro artigo, onde Aristoteles Barcelos Neto traz uma interpretação sobre a arte e a estética produzidas pelo povo Wauja do Alto Xingu a partir de sua relação com o tabaco (Nicotiana tabacum e Nicotiana rustica). Esta é planta psicoativa mais amplamente utilizada no xamanismo ameríndio, que assume ali importância como agente que transforma as pessoas e revela, através de sua fumaça e os sonhos e transes daí advindos, coisas, seres e intenções ocultos, "abrindo os olhos" de quem o consome.

O segundo capítulo, escrito por Fabiana Maizza, aborda, por sua vez, o uso do rapé e as mulheres, algo que até aqui ainda é raro na literatura, a partir da agência feminina entre indígenas Jarawara, do médio Purus. Entre o povo Jarawara, o rapé está ligado essencialmente ao feminino. Ao propor o conceito de "mulheres leváveis" para se referir à capacidade das mulheres incorporarem a qualidade xamânica de realizar viagens oníricas e espirituais, a autora contribui para a inserção das mulheres indígenas como sujeitos importantes nos debates sobre gênero e o enriquecimento das reflexões sobre o tema da sexualidade e os diferentes tabus, dicotomias e construções sociais que a ele são vinculados.

O terceiro capítulo traz uma reflexão de Joana Cabral de Oliveira sobre os usos e papeis da mandioca (Manihot esculenta) junto aos Wajãpi, do estado do Amapá. O tubérculo dá origem ao caxiri, bebida alcoólica fermentada e muito apreciada em festas e ocasiões ordinárias. Isto faz desse capítulo um ponto de inflexão importante em relação à vinculação das plantas psicoativas a contextos rituais de cunho religiosos e provoca o leitor a pensar nos diferentes lugares, papeis e agências das plantas. Plantas que não são encaradas só como objeto de consumo, mas também como companhia que influenciam os seres humanos e sua cultura, bem como os animais e outras plantas, com quem estão em constante relação de coevolução. 
O quarto capítulo, escrito por Danilo Paiva Ramos, se debruça sobre os usos de coca (Erythroxylum coca) junto aos Hupd'äh do Alto Rio Negro. Entre povos indígenas de recente contato do noroeste amazônico, o consumo tradicional de coca é altamente relevante para a vida social, além de garantir o aprendizado e proteção xamânicos e perpetuar a cultura, a história oral e a identidade do grupo. Função essa obnubilada pela "guerra às drogas", essa "guerra à vida" (p.105) que fetichiza a coca como inimiga e impede que a mesma seja vista e encarada a partir de seu lugar de planta maestra.

Um dos pontos mais impactantes da coletânea se encontra no quinto capítulo, de Miguel Aparicio, sobre a "planta da raiva", timbó (Deguelia utilis), originalmente utilizada como veneno de peixe e hoje considerada a única causa mortis entre os Suruwaha do Peru, por conta do alto índice de envenenamento "voluntário" por essa planta. As aspas aqui têm um papel importante, pois entre os Suruwaha a pessoa que morre por envenenamento de timbó não é exatamente uma suicida, mas uma "presa" dessa planta-xamã cujo poder pode perseguir e atacar as pessoas. Tal perspectiva incita profundas discussões sobre a vida, a morte, a ambiguidade das plantas e também a respeito da relação bilateral entre estas e os homens - que não só as domesticam, mas também são domesticados e guiados por elas.

Quem também se debruça sobre a ambiguidade das plantas e de sua relação com os seres humanos é Glenn Shepard Jr., que no sexto capítulo escreve sobre o sistema médicoxamânico dos Matsigenka do Peru e o uso do toé (Brugmansia suaveolens), arbusto da família das solanáceas cujas potentes propriedades psicoativas são encaradas, simultaneamente, como remédio e veneno. Capaz de revelar maravilhas e causar infortúnios, trata-se de uma planta milagrosa e traiçoeira, que remete o leitor à origem etimológica da palavra fármaco, do grego Pharmakon, termo que designava com igual propriedade substâncias capazes de causar benefícios e malefícios, e à importância do contexto sociocultural na experiência e efeitos dos psicoativos.

O último capítulo da primeira seção é de autoria de Sérgio Brissac. Trata-se do único texto da primeira parte do livro que extrapola o contexto amazônico e o uso de plantas psicoativas. Isso porque o foco do autor são as veladas mexicanas realizadas com cogumelos (Psilocybe sp.) pelos Mazatecas, no estado de Oaxaca, México. Veladas que se tornaram famosas a partir do trabalho da xamã Maria Sabina (1894-1985) com "los honguitos". Mais do que narrar os efeitos produzidos pela ingestão de cogumelos, o texto explora o poder dos sábios e sábias mazatecos em transformar seres e energias, ao transmutarem, através de suas veladas, "la oscuridad em luz, la confusión del enfermo en conocimiento, la impureza en pureza" (DEMANGET, 2000).

A despeito da heterogeneidade dos textos e suas contribuições particulares, esta seção mantém uma boa organicidade, na medida em que tem como foco claro o uso de plantas (e fungos) psicoativas por parte de povos e nações indígenas. Já a segunda seção, 
Usos indigenas e não indigenas - fluxos, interfaces e distinções, se aventura pelos sinuosos caminhos percorridos pelas plantas psicoativas a partir de sua entrada e diáspora nos contextos urbanos. Mais extensa e difusa do que a primeira seção, essa se propõe a pensar a complexidade das relações e diálogos entre indígenas e não indígenas a respeito do uso de psicoativos, abordando tensões, trocas, traduções e intermediações entre esses contextos.

O texto de Thamires Moreira traz um relato histórico sobre as formas de utilização da maconha (Cannabis sativa e Cannabis indica) no Rio de Janeiro entre os séculos XIX e XX. Ali chamada de pango, pito de pango, diamba, entre outros nomes, a maconha é analisada a partir do processo de criminalização sofrido pela planta, que não pode ser dissociado da estigmatização sofrida por determinados grupos sociais, formas culturais e práticas contra hegemônicas, em contraposição à valorização de usos médicos e autorizados. Tal reflexão nos faz pensar sobre a divisão e hierarquização de usos e saberes em voga nos processos de legalização contemporânea da maconha ao redor do mundo, a respeito da distinção social entre usos legítimos e ilegítimos de drogas, e sobre o monopólio da manipulação e consumo de psicoativos de uma forma geral.

No nono capítulo, lan Packer também escreve sobre a maconha a partir do interessante caso do povo indígena Krahô, que a denomina porhô krampej (tabaco-cabeçaboa). A partir da hipótese de que o uso da maconha entre indígenas se origina através do contato com não-indígenas, o autor mostra como ele é ressignificado pelos Krahô. Estes compreendem a cannabis como uma dádiva dos porcos-queixada e entendem que essa planta, ao lado do tabaco, é capaz de mediar as interações dos humanos entre si e destes com seres e actantes não humanos, em uma reflexão instigante sobre relações de troca e predação entre diferentes povos e espécies.

A dinâmica da interação dos Muina do rio Caquetá com os atores do conflito armado colombiano em uma área altamente militarizada e nodal nas interações geopolíticas que giram em torno da coca (Erythroxylum coca) e da "guerra às drogas" nas Américas é o grande tema do décimo capítulo, escrito por Marco Tobón. Entre povos indígenas do noroeste amazônico, o uso da coca e do tabaco, bem como os saberes tradicionais atrelados a essas plantas, cumpre uma importante função diplomática nas relações dos indígenas com agentes não indígenas - e muitas vezes violentos- presentes na região, o que faz o autor concordar com a tese de que a coca e o tabaco são sujeitos da história.

No capítulo seguinte, Alex Gearin e Beatriz Labate entregam, com base em extensa pesquisa de campo realizada em diversos países, uma ampla discussão sobre as diferenças e problemas de tradução entre os sistemas xamânicos e amazônicos e o modus vivendi ocidental, a partir das dietas prescritas para o consumo da ayahuasca (Banisteriopsis caapi e Psychotria viridis) nesses diferentes contextos. Com isso, os autores mostram como o uso da ayahuasca é constantemente reinventado e ressignificado quando transplantado para além 
das florestas tropicais sul-americanas. No limite, há barreiras intransponíveis entre as cosmologias indígenas e ocidentalizadas, que tornam o consumo global da ayahuasca algo complexo, que ao mesmo tempo opera uma aproximação e um afastamento entre xamãs indígenas e terapeutas urbanos, bem como entre a cidade e a floresta.

Os três capítulos seguintes trazem contribuições que se alinham em uma proposição tão instigante quanto contraintuitiva, a saber, que as próprias tradições indígenas de consumo da ayahuasca se beneficiaram e foram até mesmo reavivadas pelo contato de indígenas com as sincréticas religiões ayahuasqueiras brasileiras, em especial o Santo Daime. Tal reflexão complexifica e enriquece bastante o debate sobre tradição, usos originários, apropriação cultural e legitimidade que tem emergido no cenário ayahuasqueiro, acadêmico ou não, de modo geral.

No décimo segundo capítulo, Guilherme Meneses estuda os rituais de Nixi Pae (ayahuasca) entre os Huni Kuin com base nas mediações e relações de troca entre esse povo e adeptos do Santo Daime. Com isso, o autor demonstra como as alianças realizadas pelos Kaxinawá com atores não-indígenas, humanos ou não, operam transformações e atualizações na vida da aldeia e contribuem para a valorização da cultura do Nixi Pae entre os Huni Kuin, e destes pelo público New Age ocidentalizado.

Nesta mesma linha de argumentação, Aline Ferreira Oliveira aborda o uso não só da ayahuasca, mas também de outras das chamadas "medicinas da floresta", o rapé (feito de tabaco e cinzas de diversas plantas, que variam de acordo com a etnia que o utiliza) e a sananga (Tabernaemontana sananho), ainda subrepresentados na literatura acadêmica. Com foco especialmente na perspectiva dos Yawanawa e seu trânsito entre a floresta e a cidade, a autora traz insights sobre a relação dialógica entre a ontologia multiculturalista e multinaturalista presentes concomitantemente no universo do novo campo xamânico e de seus fluxos entre indígenas e nawas (não-indígenas).

Por sua vez, o texto de Saulo Conde Fernandes sintetiza a multiplicidade de trânsitos e atualizações presentes no (neo)xamanismo contemporâneo, mais especificamente no circuito urbano da ayahuasca, tomando por base o conceito de tradições inventadas e tendo como eixo central a estruturação rizomática de grupos e atores do Santo Daime e as "alianças" estabelecidas por esses junto a indígenas e neoayahuasqueiros. Merecem especial destaque as trocas de medicinas realizadas entre daimistas e indígenas: enquanto aqueles absorveram o uso do rapé e da sananga por meio dos segundos, esses entraram em contato com a maconha a partir da mitologia daimista da "Santa Maria", que vincula o uso da cannabis à figura bíblica da mãe de Jesus.

As organizadoras da coletânea, Sandra Goulart e Beatriz Labate, são também responsáveis pelo décimo quinto capítulo, que procura analisar em profundidade a organização e efeitos da II Conferência Mundial da Ayahuasca, realizada em Rio Branco (AC) 
em outubro de 2016 pela ONG espanhola ICEERS. Este evento, que congregou um número sem precedentes de pessoas e grupos envolvidos com a temática da ayahuasca, é utilizado pelas autoras como pano de fundo de discussões sobre o crescente protagonismo indígena no cenário urbano da ayahuasca, o processo de patrimonialização da bebida e as controvérsias que envolvem a polissemia de sentidos, epistemologias e interesses que orbitam em torno desse psicoativo.

Se distanciando - pero no mucho - das discussões em torno da ayahuasca que dão a tônica da segunda parte da coletânea, o capítulo de Rodrigo Grünewald e Robson Savold aborda os contextos e usos da jurema (especialmente a Mimosa tenuiflora, ou "jurema preta") em perspectiva histórica ampliada, que vai das raízes rituais do catimbó ao psiconautismo contemporâneo. Nesse âmbito, as experimentações da jurema com outras plantas, notadamente a arruda da síria (Perganum harmala), a fim de extrair efeitos psicoativos de maior intensidade, têm influenciado uma variada gama de juremeiros que fazem uso ritual (religioso ou não) da planta.

Por fim, o último capítulo traz as contribuições de Isabel Santana de Rose a respeito do cacto peiote (Lophophora williamsii). Ao discutir três questões distintas e complementares (resenha de uma coletânea sobre o cacto, reflexões sobre o Fogo Sagrado de Itzachilatlan e apontamentos a respeito do processo de legalização do uso ritual/religioso do peiote no Brasil), a autora ajuda a preencher a lacuna da literatura em português sobre o peiote, aproveitando para abordar sua diáspora internacional e diversidade de usos em perspectiva comparativa com o caso da ayahuasca, com o qual apresenta várias similaridades e contrastes interessantes.

A partir do que precede, podemos perceber que $O$ uso de plantas psicoativas nas Américas procura abarcar uma extensa gama de discussões em torno do uso de plantas psicoativas, que envolvem um número impressionante de substâncias, agentes e territórios. A amplitude desse projeto ambicioso tem um caráter um tanto paradoxal. Ao mesmo tempo em que é responsável por grandes méritos da obra, como o vasto escopo de estudo e a diversidade de etnografias, povos e substâncias abordadas, também está diretamente implicada em algumas lacunas e ruídos que podem ser percebidos na coletânea.

Apesar de tratar das Américas de um modo geral, o livro tem como foco principalmente a Amazônia ocidental, a partir de estudos majoritariamente realizados por brasileiros residentes no Brasil. Nesse sentido, apesar de trazer estudos sobre o contexto estadunidense e mexicano, e até mesmo uma etnografia realizada na Austrália, faltam pesquisas sobre o Caribe, América Central, Chile, Argentina, Paraguai, dentre outros países relevantes na cartografia sociobiocultural das Américas.

Da mesma maneira, embora o livro aborde mais de uma dezena de plantas psicoativas e reserve espaço inclusive para animais (kambô) e fungos (cogumelos), 
importantes plantas e substâncias psicoativas utilizadas nas Américas foram deixadas de lado, desde algumas menos conhecidas como Salvia divinorum e Bufo alvarius, até aquela que está entre as plantas de maior relevância histórica para o continente Americano, o café.

Outro pequeno problema é a divisão da coletânea em duas sessões. Como vimos, a primeira é bastante coesa, apresentando pesquisas e reflexões cujo eixo central são as sociedades indígenas em suas relações com plantas sagradas. Já a segunda, não obstante dê a entender que se atém à "complexidade e a riqueza das relações entre ambos os contextos" (indígena e não indígena), na prática acolhe todo tipo de discussão e estudo que não esteja exclusivamente vinculado a contextos indígenas, desde o uso de maconha na cidade do Rio de Janeiro do século XIX até a II Conferência Mundial da Ayahuasca, o que quebra um pouco a fluidez e organicidade da obra. Esse, entretanto, é um problema menor de forma, muito mais do que de conteúdo, que não compromete a qualidade da obra em absoluto.

Esta coletânea se trata de um autêntico e poderoso sucessor do Uso Ritual das Plantas de Poder (GOULART; LABATE, 2005), organizado pelas mesmas pesquisadoras há 15 anos e que até hoje ocupa lugar de destaque na literatura brasileira sobre plantas psicoativas. O uso de plantas psicoativas nas Américas é sem dúvida uma das melhores demonstrações do "estado da arte" das pesquisas sobre plantas sagradas nas Américas, especialmente no Brasil e na Amazônia Ocidental. O livro consegue ilustrar com propriedade a crescente e ainda pouco abordada emergência dos indígenas como atores cada vez mais relevantes nos fluxos urbanos globais de uso ritual de plantas psicoativas.

Um livro paradigmático, que desafia a visão hegemônica de que a vida social, religiosa e cultural pode ser exercida unicamente através de um pretenso "estado natural" de consciência, que exclui o consumo de psicodélicos e os saberes tradicionais como potencialmente produtivos e positivos para a vida humana. Uma obra que demonstra a necessidade de se estabelecer novos parâmetros para que seja possível lidar com as plantas psicoativas, suas formas de uso e de coexistência junto aos seres humano no século XXI, um cenário tão particular e auspicioso para as ciências sociais quanto foi a alvorada da dita "modernidade". Cenário cujos dilemas, tesouros e mistérios as organizadoras do presente volume nos ajudam a desvendar.

\section{REFERÊNCIAS}

DEMANGET, Magali. El precio de la tradición: em torno a los intercâmbios entre riqueza económica y espiritual em la comunidade mazateca de Huautla de Jimenez, Oaxaca. Cuadernos de Trabajo, n. 6, Xalapa: Instituto de Investigaciones Histórico-Sociales, Universidad Veracruzana, 2000.

GOULART, Sandra; LABATE, Beatriz (0rg.). 0 uso ritual das plantas de poder. Campinas: Mercado das Letras, 2005. 
LABATE, Beatriz; GOULART, Sandra (Org.) 0 uso de plantas psicoativas nas Américas. Rio de Janeiro: Gramma/NEIP, 2019.

LATOUR, Bruno. Reagregando o social: uma introdução a teoria do ator-rede. Salvador-Bauro: EDUFBA-EDUSC, 2012.

STENGERS, Isabelle. A proposição cosmopolítica. Revista Do Instituto De Estudos Brasileiros, n. 69, p. 442-464, 2018.

VIVEIROS DE CASTRO, Eduardo. Os pronomes cosmológicos e o perspectivismo ameríndio. Mana,v. 2, ก. 2, p. 115-144, 1996. 